\section{Turkish Journal of Agricultural Engineering Research}

https://dergipark.org.tr/en/pub/turkager

https://doi.org/10.46592/turkager.2020.v01i02.007
Turk J Agr Eng Res

(TURKAGER)

e-ISSN: $2717-8420$

2020, 1(2): $296-310$

Research Article (Araştırma Makalesi)

\title{
Sodyum Aljinat Kaplama Uygulamalarının Az İşlem Görmüş Elma Kalitesine Etkileri
}

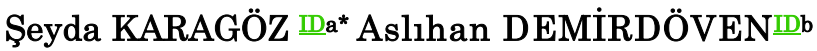 \\ ${ }^{a}$ Gıda Teknolojisi Bölümü, Zile Meslek Yüksekokulu, Tokat Gaziosmanpaşa Üniversitesi, Zile, Tokat, TÜRKIYE \\ ${ }^{b}$ Gıda Mühendisliği Bölümü, Mühendislik ve Mimarlık Fakültesi, Tokat Gaziosmanpaşa Üniversitesi, Tokat, TÜRKIYYE \\ (*): Corresponding author, seydakaragoz@gop.edu.tr; Tel: +90-356-2521616 (2899)
}

\section{ÖZET}

Bu çalışmada, Amasya çeşidi elma küplerinin sodyum aljinat (SA) ve stevia kombinasyonları (SAS) içeren çözeltiler ile kaplanması ve modifiye atmosferde (MAP) depolanması sonucu meydana gelen bazı fiziksel ve kimyasal kalite değişimleri incelenmiştir. Araştırma sonucunda; 3 gün depolanan kaplanmış ve kaplanmamış örneklerde (K) ağırlık kaybı gözlenmemiştir. Solunum hızı verileri incelendiğinde K, SA ve SAS örnekleri için sırasıyla oksijen tüketimi 82.95; 26.53 ve $230.56 \mathrm{ml} \mathrm{kgs}^{-1}$. (24sa), karbondioksit üretimi 193.55; 25.21 ve $157.00 \mathrm{ml} \mathrm{kgs}^{-1}$ (24sa) olarak tespit edilmiştir. Depolama başlangıcında titrasyon asitliği değerleri K, SA ve SAS örnekleri için sirasıyla \%0.055, \%0.118 ve \%0.125 ve meyve sertliği değerleri sirasıyla 2.458, 1.665 ve $1.430 \mathrm{~N}$ olarak belirlenmiştir. K, SA ve SAS örnekleri için 0.gün/3. gün $L^{*}$ değerleri; 79.84/67.50;77.64/65.65 ve 69.46/42.94, $a^{*}$ değerleri, -1.44/4.04;-3.15/3.94 ve $-3.04 / 18.63$ ve $b^{*}$ değerleri 16.66/35.85;19.23/54.01 ve 28.01/46.68 olarak ölçülmüştür. Ayrıca, SA'nın yapışkanımsı özellik katması ve stevianın otsu kokusu ve tadı nedeniyle aljinat ve stevia kombinasyonu film kaplı örnekler duyusal olarak kabul görmemiştir. Sonuç olarak kaplama uygulamalarının solunum hızını azalttığı, titrasyon asitliği değerini arttırdığı ve doku değerini azalttığı belirlenmiştir.

\section{ARAŞTIRMA MAKALESI}

Alınış tarihi: 29.06.2020

Kabul tarihi: 27.08.2020

Anahtar Kelimeler:

$>$ Elma,

$>$ Raf ömrü,

> Sodyum aljinat,

$>$ Stevia,

$>$ Yenilebilir film

Alıntı için: Karagöz Ş, Demirdöven A (2020). Sodyum Aljinat Kaplama Uygulamalarının Az İşlem Görmüş Elma Kalitesine Etkileri. Turkish Journal of Agricultural Engineering Research (TURKAGER), 1(2): 296-310. https://doi.org/10.46592/turkager.2020.v01i02.007 


\title{
Effects of Sodium Alginate Coatings on Quality of Fresh-Cut- Apples
}

\begin{abstract}
In this study, some physical and chemical quality changes that occurred as a result of coating Amasya variety apple cubes with solutions containing sodium alginate (SA) and stevia combinations (SAS), and storage in modified atmosphere (MAP) were investigated. As a result of the research, no weight loss was observed in the coated and uncoated samples (K) stored for 3 days. When respiratory rate data are analyzed, oxygen consumption for K, SA and SAS samples has been determined as 82.95, 26.53 and $230.56 \mathrm{ml} \mathrm{kgs}^{-1}(24 \mathrm{~h})$ and the carbon dioxide production was $193.55,25.21$ and $157.00 \mathrm{ml} \mathrm{kgs}^{-1}$ (24h), respectively. Titration acidity values at the beginning of storage were determined as $0.055 \%, 0.1118 \%$ and $0,125 \%$ for $\mathrm{K}$, SA and SAS samples, and fruit hardness values determined as 2.458, 1.665 and $1.430 \mathrm{~N}$, respectively. The 0 th/3rd day $L^{*}$ values for $\mathrm{K}$, SA and SAS samples were measured as $79.84 / 67.50$, $77.64 / 65.65$ and $69.46 / 42.94, a^{*}$ values as $-1.44 / 4.04,-3.15 / 3.94$ and $-3.04 / 18.63$, and $b^{*}$ values as $16.66 / 35.85,19.23 / 54.01$ and 28.01/46.68. Due to the adherent feature of SA and the herbaceous smell and taste of stevia, coated samples with the combination of alginate and stevia were not acceptable as sensory. As a result, it has been determined that coating applications decrease respiration rate, increase titration acidity value and decrease hardness value.
\end{abstract}

\section{RESEARCH ARTICLE \\ Received: 29.06 .2020 \\ Accepted: 27.08 .2020 \\ Keywords: \\ $>$ Apple, \\ $>$ Shelf life, \\ $>$ Sodium alginate, \\ $>$ Stevia, \\ $>$ Edible film}

To cite: Karagöz Ş, Demirdöven A (2020). Effects of Sodium Alginate Coatings on Quality of Fresh-Cut-Apples. Turkish Journal of Agricultural Engineering Research (TURKAGER), 1(2): 296-310. https://doi.org/10.46592/turkager.2020.v01i02.007

\section{GİRİ̧}

Toplumların hazır gıdalara olan ilgisi; kadınların çalışma hayatına başlaması, insanların trafikte fazla zaman geçirmesi, iş hayatındaki yoğun tempo gibi nedenlerden dolayı giderek artmaktadır. Bu nedenle gıda sektöründeki birçok firma ve bilim insanları çalışmalarını tüketimi hazır olan gıdalara yönlendirmiştir. Bu yönelim doğrultusunda yapılan çalışmalar özellikle bazı meyve ve sebzelerin parçalanmast/kesilmesi işleminde polifenol oksidaz enziminin fenolik bileşiklerle teması sonrasında meydana gelen enzimatik esmerleşme üzerine yapılmaktadır. Oluşan bu problemin çözülmesinde; ısıl işlem uygulamaları (haşlama, pastörizasyon, ohmik ısıtma vb.), enzimatik esmerleşme karşıtı kimyasal ajanların kullanımı (antioksidanlar), ışınlama uygulamaları ve çeşitli alternatif yöntemler (mikrodalga, vurgulu elektrik alan, yüksek basıç uygulaması vb) kullanılmaktadır. Ancak bu uygulamaların çoğu taze meyvelerde dokusal zarar oluşturduğu için kullanılamamaktadır (Yılmaz ve Elmacı, 2018; Karagöz, 2018).

Yenilebilir filmlerin kullanımı ile bu noktada birçok avantaj elde edilmektedir. Yenilebilir filmler meyveyi dışarıdan bir film gibi sararak meyvenin oksijen ile temasını kesmekte ve polifenol oksidaz enziminin faaliyetini yavaşlatmaktadır. Bununla birlikte 
formülasyona eklenen antioksidan ajanın meyveye difüze olmasını yavaşlatmakta ve daha uzun bir süre oksijene karşı koruma sağlamaktadır. Ancak her film ya da formülasyon her ürün için aynı özellik göstermemektedir. Bu nedenle araştırmacılar tarafından farklı formülasyonlarda ve farklı meyveler için kaplama çalışmaları yapılmaktadır. Bu noktada avantajlı olacağı düşünülen sodyuma aljinat yenilebilir film olarak çalışmada tercih edilmiştir (Karagöz, 2018).

Bir polisakkarit olan sodyum aljinat, iyi koloidal özellikleri ve sulu çözeltilerde güçlü jel oluşturabilme kabiliyeti nedeniyle başta gıda, ilaç ve kozmetik endüstrisi olmak üzere birçok alanda değerlendirilmeye başlanmıştır (Chen ve ark., 2016). Sodyum aljinatlar sert moleküler zincir ve iyi bir film oluşturabilme özelliğine sahiptir (Siddaramaiah ve ark., 2008). Bu nedenle et, balık ve meyvelerin dehidrasyonunu sınırlamak için yenilebilir film olarak veya kapsülleme ajanı olarak da kullanılabilmektedir (Pop ve ark., 2015). Öte yandan toksik olmaması, biyobozunur, biyouyumlu ve düşük maliyetli olması nedeniyle film üretiminde önemli bir bileşen olarak görülmektedir (Tavassoli-Kafrani ve ark., 2016).

Sodyum aljinat bazlı filmler kavun, papaya ve az işlem görmüş elmalarda dokuyu geliştirmekte, su kaybını azaltmakta, fizikokimyasal, mikrobiyolojik ve antioksidan özellikleri korumaktadır (Olivas ve ark., 2007; Oms-Oliu ve ark., 2008a; Tapia ve ark., 2008). Sodyum aljinat bazlı filmler antioksidan, antimikrobiyal renklendiriciler gibi çeşitli katkı maddelerin taşıyıcısı da olabilmektedir (Rössle ve ark., 2011). Bundan yola çıkarak bu çalışmada sodyum aljinat çözeltisine antioksidan özelliği nedeniyle askorbik asit ilave edilmiştir. Ayrıca birçok çalışmada tatlandırıcı, antioksidan ve antimikrobiyal vb. özellik gösterdiği belirtilen stevia bitkisi kullanılmıştır.

Stevia rebaundiana bitkisi Güney Amerika orijinli ekstraktları kalorisiz, doğal bir tatlandırıcı olarak yıllardır Japonya, Çin, Kore ve Brezilya başta olmak üzere birçok ülkede kullanılmaktadır (Gantait ve ark., 2015). Stevia rebaundiana, antimikrobiyal ve antioksidan özelliklere sahip olan fenolik bileşikleri, C vitaminini, karotenoidler ve klorofilleri yüksek miktarda içermektedir (Barba ve ark., 2015).

$\mathrm{Bu}$ çalışmanın diğer birçok çalışmadan farkı taze kesilmiş Amasya çeşidi elmalara uygulanmasıyla birlikte, kaplanmış elmaların modifiye atmosfer koşullarında depolanmasıdır. Amasya elma çeşidi diğer elma çeşitlerine göre çok daha fazla enzimatik esmerleşme göstermektedir. Bu elma çeşidindeki enzimatik esmerleşmenin durdurulması ile soydum aljinat yenilebilir filminin diğer elma çeşitlerinde de kullanımı mümkün olabilecektir. Yenilebilir film ve modifiye atmosferde paketleme uygulamalarının birlikte kullanılması üzerine yapılan çalışmalar sınırlıdır. Modifiye atmosferde paketleme; ambalajdaki normal gaz atmosferinin tepe boşluğuna verilen gaz ile optimum koşullara en yakın olacak şekilde değiştirildiği ve böylece ambalajlı ürünün raf ömrünün uzatılmasının amaçlandığı bir metot olarak tanımlanabilmektedir (Fişekçi, 2013, Karagöz, 2018).

Bu çalışmada az işlem görmüş Amasya çeşidi elmanın (Amasya misketi) sodyum aljinat yenilebilir filmi ve stevia içeren kombinasyonları ile kaplanması ve bunların pasif modifiye atmosferde paketleme (MAP) koşullarında depolanması ile meydana gelen bazı kalite değişimlerinin belirlenmesi amaçlanmıştır. 


\section{MATERYAL ve YÖNTEM}

Materyal: Çalışmada Amasya çeşidi elma kullanılmıştır. Kaplama çözeltisinin oluşturulmasında materyal olarak orta viskoziteli sodyum aljinat (2.000 cp, \%2, Sigma), gliserol (Sigma-Aldrich, Almanya), askorbik asit (1.65 g/ $\mathrm{cm}^{3}$, E300, Tito, Çin) ve yerel bir aktardan temin edilen (Tokat, Türkiye) kurutulmuş stevia yaprakları kullanılmıştır. MAP uygulaması için polipropilen $(\mathrm{PP}-30 \mu \mathrm{m})$ ambalaj materyali tercih edilmiştir.

Sodyum aljinat ve sodyum aljinat-stevia film formülasyonu: Sodyum aljinat içeren kaplama çözeltisi üretimi için \%1.25 (a/h) sodyum aljinat kullanılmıştır. Ayrıca \%10 (h/h) gliserol (plastikleştirici) ve \%2 askorbik asit (antioksidan ajan) ilave edilmiştir (kaplama çözeltisinin hazırlanmasına ait deyatlı bilgi Karagöz (2018)'den bu oranlar ön denmelerle belirlenmiştir.). Hazırlanan çözelti bir saat boyunca $45{ }^{\circ} \mathrm{C}$ 'de homojenize edilmiş, ultrasonik banyoya (Elmasonic S 100 (H), Elma, Almanya) konularak 30 dakika boyunca kaplama çözeltisi içindeki $\mathrm{O}_{2}$ miktarını azaltmak amacıyla degaz işlemine tabi tutulmuştur (Chiabrando ve Giacalone, 2016). SAS kaplama çözeltisi üretimi için ise yukarıda belirtilen oranlara ek olarak konsantrasyonu \%2.5 olacak şekilde stevia özütü eklenmiştir. Özüt, 8.33 g Stevia rebaudiana kuru yaprakları üzerine $100{ }^{\circ} \mathrm{C}$ 'deki $100 \mathrm{ml}$ saf suyun eklenmesi ve 30 dakika bekletilmesi ile elde edilmiştir. Bu oran daha önce yapılan çalışmalarda en iyi antimikrobiyal etkiyi göstermesi nedeniyle seçilmiştir (Carbonell-Capella ve ark., 2015).

Yenilebilir filmlerin elma dilimlerine uygulanmass: Elmalar işlem öncesi musluk suyu ile yıkanmış, kurulanmış ve küp $\left(1.8 \times 1.8 \times 1.8 \mathrm{~cm}^{3}\right)$ şeklinde kesilmiştir. Ardından elmalar enzimatik esmerleşme göstermeden hızlı bir şekilde kaplama çözeltisine daldırılmış (oda sıcaklığı) ve 30 dakika bekletilmiştir. Çözeltiden çıkarılan elmalar 20 dakika delikli levha üzerinde süzülmüş ve 120 dakika oda şartlarındaki etüvde $(25 \pm 2$ ${ }^{\circ} \mathrm{C}$, Memmert 100-800, Schwabach, Germany) kurutulmuştur. Sonrasında pasif MAP koşullarını sağlamak için, kaplanmamış ve kaplanmış elmalar uygun boyutlarda $\left(20 x 30 \mathrm{~cm}^{2}\right)$ ambalaj (PP) içerisine yerleştirilerek ısıl yapıştırıcı ile kapatılmış (Packtech, impulse sealer FS 400 for PP/PE), 3 gün süreyle pasif MAP koşullarında (başlangıç gaz komposizyonu: \%21 $\mathrm{O}_{2}, \% 0.03 \mathrm{CO}_{2}$ ve diğer gazlar) $1 \pm 1{ }^{\circ} \mathrm{C}$ 'de \%80-90 bağıl nemde depolanmıştır (Capri, CSS 501, $1.38 \mathrm{~m}^{3} \pm 2$, Türkiye).

\section{Analiz Yöntemleri}

Solunum hızi: Gaz ölçümleri Gaspace 2 marka (İngiltere) gaz analizatörü kullanılarak yapılmıştır. Kontrol örneği ve kaplanmış örneklerden 1'er kg örnek alınarak 5 litrelik kavanozlara yerleştirilen örneklerde 24 saat sonundaki $\%_{2}$ ve $\quad \mathrm{O}_{2}$ konsantrasyonları ölçülmüss ve bu değerler kullanılarak solunum hızları hesaplanmıştır (1, 2) (Demirdöven, 2003).

Solunum hızı, $\mathrm{ml} \mathrm{O}_{2} \cdot \mathrm{kg}^{-1} \cdot \mathrm{sa}^{-1}=(\mathrm{A}-\mathrm{B}) * \mathrm{~V} / 100$

Solunum hızl, $\mathrm{ml} \mathrm{CO}_{2} \cdot \mathrm{kg}^{-1} \cdot \mathrm{sa}^{-1}=\mathrm{C} * \mathrm{~V} / 100$

A: Başlangıç O2 konsantrasyonu, \%; B: Son O2 konsantrasyonu, \%; C: Son CO2 konsantrasyonu, \%; $\mathrm{V}$ : Kavanozdaki havanın hacmi, ml 
Titrasyon asitliği: Homojenize edilmiş 15 g elma örneği, 150 ml'lik erlene konarak üzeri sıcak su ile tamamlanmış, ağzı kapalı olarak 2 saat bekletilmiştir. Bekletme sonrası filtreden geçirilmiştir. Hazırlanan örnek, seyreltme faktörü dikkate alınarak \% malik asit (g/100 g meyve) cinsinden hesaplanmıştır (Stevens ve ark., 1979).

Ağırlık kaybı (\%): Ağırlık kaybı elmaların başlangıç ve raf ömrü sonundaki tartımları yapılarak \% olarak ifade edilmiştir (Tokatlı, 2016).

Doku değeri: Elmalar dikey boyutundan $10 \mathrm{~mm}$ delmek için gereken maksimum kuvvet Newton cinsinden ölçülerek belirlenmiştir. Ölçümde, $10 \mathrm{~mm}$ çapında paslanmaz çelik başlığa sahip Zwick Z 0.5 (USA) model test cihazı kullanılmıştır (Anonim, 2002).

Meyve eti rengi değişimleri: Elmalarda meyve eti rengi meyve kabuğu içermeyen yüzeyde, Minolta renk ölçüm cihazı (Chroma meter, CR-300, Japonya) beyaz ve siyah standart bir plakada kalibre edildikten sonra, Hunter CIE Lab renk ölçüm parametreleri ile $L^{*}$ (parlaklık), $a^{*}$ (kırmızı/yeşil), $b^{*}$ (sarı/mavi) değerleri elma üzerinde üç farklı noktada ölçülerek belirlenmiştir (Anonim, 1991).

$L^{*}$ parlaklık/aydınlık değeri 0'a yaklaştıkça koyu (siyah), 100'e yaklaştıkça açık (beyaz); $a^{*}$ değeri + ise kırmızı, - ise yeşil; $b^{*}$ değeri + ise sarı, - ise mavi koordinatlarını göstermektedir (Anonim, 1996). Ayrıca kırmızılık ve sarılık değerlerini birlikte ele alan ve metrik renk kroması olarak tanımlanan $\Delta \mathrm{C}$ değeri, rengin doygunluğunu (yoğunluk) göstermekte ve canlı renklerde yüksek, donuk renklerde düşük görülmektedir. Renk tonu ölçüsü olan Hue açısı (a) değeri bir renk dairesi olarak tanımlanmakta ve kırmızı, sarı, yeşil ve mavi renkleri $0^{\circ}, 90^{\circ}, 180^{\circ}$ ve $270^{\circ}$ açılarda konumlanmaktadır (McGuire, 1992; Luo, 2006; İzli ve Polat, 2016). $\Delta \mathrm{E}$ değeri ise toplam renk değişimini ifade etmektedir.

Analiz sonrası belirlenen $\mathrm{L}^{*}$, $\mathrm{a}^{*}$ ve $\mathrm{b}^{*}$ değerleri kullanılarak $\Delta \mathrm{E}, \Delta \mathrm{C}$ ve Hue açısı değerleri hesaplanmıştır $(3,4,5)$ (hesaplamalar için kontrol örneğinin 0 . gün $\mathrm{L}^{*}, \mathrm{a}^{*}$ ve $b^{*}$ değerleri dikkate alınmıştır).

$$
\begin{aligned}
& \Delta \mathrm{E}=\left[\left(\mathrm{L}^{*}-\mathrm{L}_{\mathrm{ref}}{ }^{*}\right)^{2}+\left(\mathrm{a}^{*}-\mathrm{a}_{\mathrm{ref}}{ }^{*}\right)^{2}+\left(\mathrm{b}^{*}-\mathrm{b}_{\mathrm{ref}}{ }^{*}\right)^{2}\right]^{1 / 2} \\
& \Delta \mathrm{C}=\left[\left(\mathrm{a}^{*}-\mathrm{a}_{\mathrm{ref}}\right)^{2}+\left(\mathrm{b}^{*}-\mathrm{b}_{\mathrm{ref}}\right)^{*}\right]^{1 / 2} \\
& \text { Hue açısı }=\tan ^{-1}\left(\mathrm{~b}^{*} / \mathrm{a}^{*}\right)
\end{aligned}
$$

Duyusal analiz: Örnekler tatlılık, ekşilik, elma aroması, gevreklik, sertlik ve kabul edilebilirlik açısından değerlendirilmiştir. Duyusal analiz, 9 panelist tarafından her bir özellik için 0-5 puan üzerinden grafik skala kullanılarak yapılmıştır. Söz konusu skalada panelist tarafından işaretlenen bölümün ortalama değerleri baz alınmıştır (Altuğ ve Elmacı, 2005).

İstatistiksel analiz: İstatistiksel değerlendirmeler SPSS 16 paket programı kullanılarak yürütülmüştür. Uygulamaya ait farklılıklar, örnek grupları ile depolama süresi-örnek grupları interaksiyonları ait karşılaştırmalar, ilişkili örneklemeler için "tek faktör Anova (One-Way Anova for Repeated Measures)" analizine göre değerlendirilmiştir. Ortalama değerler \%95 güven düzeyinde “Tukey” çoklu karşılaştırma testi ile karşılaştırılmıştır (Tokatlı, 2016). 


\section{BULGULAR ve TARTIŞMA}

\section{Solunum hizı}

Örneklerin solunum hızlarına ait veriler Şekil 1'de verilmiştir. Örnekler arasındaki oksijen tüketimi en fazla SAS örneğinde ve karbondioksit üretimi en fazla K örneğinde görülmüştür $(\mathrm{P} \leq 0.05)$. Üç grubun 24 saat sonundaki $\mathrm{O}_{2}$ tüketimi $\mathrm{K}$, SA, SAS için sırasıyla; 82.95, 26.53, $230.56 \mathrm{ml} \mathrm{kgh}^{-1}(24 \mathrm{~h}), \mathrm{CO}_{2}$ üretimi $\mathrm{K}$, SA, SAS için sırassyla; $193.55,25.2$ ve $157 \mathrm{ml} \mathrm{kgh}^{-1}$ (24h) olarak bulgulanmıştır. Verilerde görüldüğü üzere sodyum aljinat film çözeltisi ve stevia içeren kombinasyonları solunum hızını azaltmıştır. Karagöz ve Demirdöven (2019) kitosan ve stevia kombinasyonlarının taze kesilmiş Amasya elması üzerinde yaptığı çalışmada da benzer sonuçlar elde etmiştir. Ancak her iki çalışma değerlendirildiğinde stevianın farklı film bileşenleri için farklı tepkimeler gösterdiği anlaşılmaktadır. Stevia, kitosan ile kullanıldığında solunum hızını daha da yavaşlatırken sodyum aljinat ile kullanıldığında sodyum aljinata göre solunum hızını arttırmıştır.

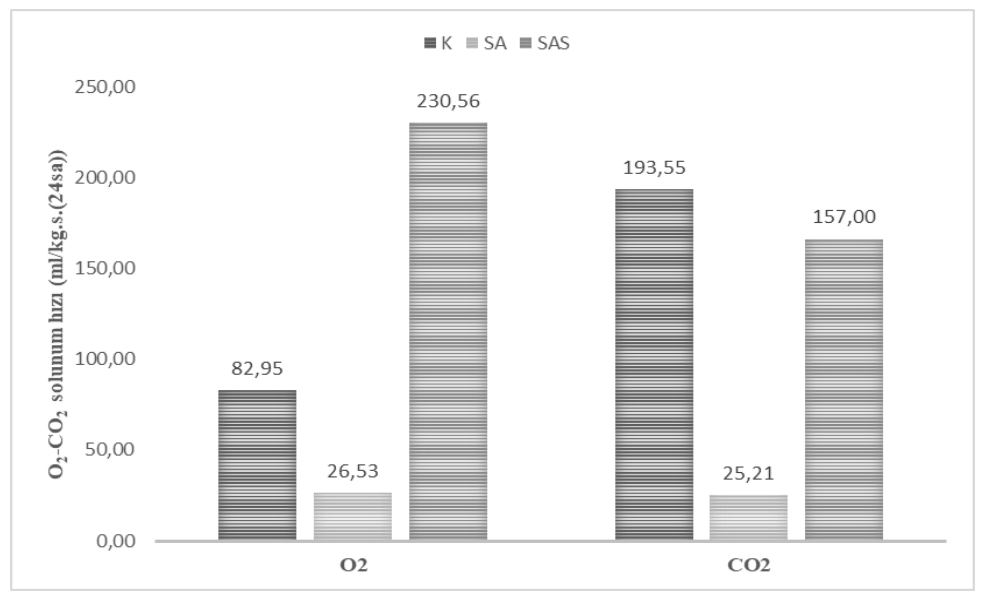

Şekil 1. Örneklerinin solunum hızı değerleri K (Kontrol), SA (Sodyum aljinat), SAS (Sodyum aljinat-stevia)

Figure 1. Raspiration rates of samples; $C$ (Control), $S A$ (Sodium alginate), SAS (Sodium alginate-stevia)

Bir ürünün solunum hızı, birim ağırlığın birim zaman içinde solunum sonucu ürettiği $\mathrm{CO}_{2}$ veya solunumda kullandığı $\mathrm{O}_{2}$ 'in miktarıdır. Bu nedenle solunum hızı ile ürünün metabolizma hızı anlaşılabilmektedir (Batu ve Demirdöven, 2010). Meyve ve sebzelerin solunum hızları ile raf ömürleri arasındaki ilişki esas alındığında, bir ürünün solunum hızı ne kadar yüksekse depolanma ömrü de o kadar kısalmaktadır (Cemeroğlu ve ark., 2001). Bununla birlikte yenilebilir kaplamalar oksijen, karbondioksit, nem ve katı maddelerin hareketine karşı yarı geçirgen bir yapı sağlayarak, solunum hızını, su kaybını ve oksidatif reaksiyonları azaltmaktadırlar (Baldwin ve ark., 1995; Perez-Gago ve ark., 2010; Öz ve Süfer, 2012). Bu çalışmada gaz ölçümü verilerinde görüldüğü üzere, film kaplama solunum hızını etkilemiş olup stevia, karbondioksit üretim hızını sodyum aljinat kaplamaya göre arttırmıştır. Bununla ilgili olarak yapılan bir başka çalışmada, Ficus hirta meyve ekstraktı içeren ve içermeyen \%1.5 SA yenilebilir kaplamalar ile Nanfeng mandalinalarını kaplamışlardır. Araştırmacılar Ficus hirta+SA kaplı örneklerin solunum hızını kontrol örneğine göre çok daha düşük bulmuştur (Chen ve ark., 2016). 


\section{Titrasyon Asitliği}

Sodyum aljinat ve sodyum aljinat+stevia kaplı örneklerin titrasyon asitliği değerleri kontrol örneği değerlerine göre yüksek bulunmuştur $(\mathrm{P} \leq 0.05)$. Bununla ilgili olarak yapılan bir çalışmada tüm örnekler için 14 günlük depolama süresi boyunca titrasyon asitliğinde bir miktar düşüş gözlenmiştir ve kontrol örneği elma dilimleri genel olarak en yüksek değerlere sahipken, prebiyotik içeren kaplama ile kaplı dilimler en düşük değerleri göstermiştir (Rössle ve ark., 2011). Ancak bu çalışmada görülen farklılığın sodyum aljinat kaplama çözeltisine eklenen askorbik asitten kaynaklandığı düşünülmektedir. Ayrıca SA örneği ile SAS örneğinin arasındaki fark istatistiki olarak önemli bulunmamıştır ( $\mathrm{P}>0.05)$ (Şekil 2).

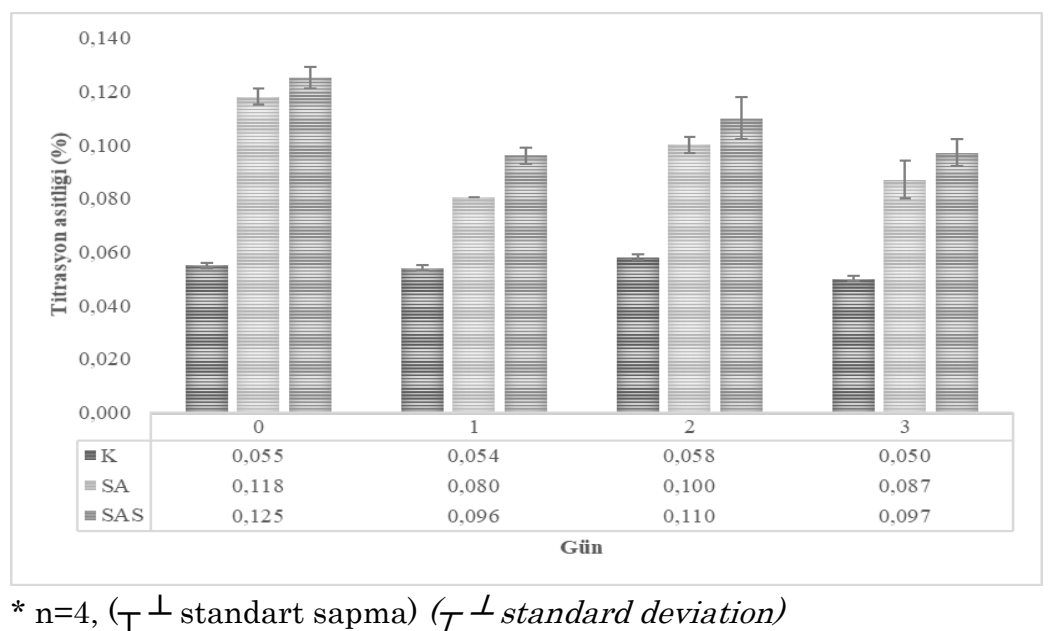

Şekil 2. Örneklerin titrasyon asitliği değerleri K (Kontrol), SA (Sodyum aljinat), SAS (Sodyum aljinat-stevia)

Figure 2. Titration acidity values of samples; $C$ (Control), $S A$ (Sodium alginate), $S A S$ (Sodium Alginate-stevia)

Meyveler depolama sırasında solunumlarında şekerlerin yanı sıra organik asitlerden de yararlanabilmektedir ve bu nedenle depolanmış meyvelerde asit miktarında azalma görülebilir (Cemeroğlu, 2004). Sadler ve Murphy (1998)'e göre de şeker içeriği arttıkça, meyvelerdeki asitler meyvenin olgunlaşmasıyla birlikte azalma eğilimi gösterirler. Bununla birlikte $\mathrm{K}$, SA ve SAS örneklerinin 0.gün/3.gün değerleri sirasıyla $\% 0.055 / 0.050 ; \% 0.118 / 0.087 ; \% 0.125 / 0.097$ olarak tespit edilmiştir. Örneklerin asitlik değerlerinde depolama sonunda düşüş gözlenmiştir ve bu düşüş istatistiki olarak önemlidir $(\mathrm{P} \leq 0.05)$. Nitekim yapılan bir çalışmada depolama boyunca tüm işlemlerde malik asit konsantrasyonu azalmıştır ve kontrol örneği ile işlem görmüş elmalar arasında önemli bir fark bulunmamıştır (Olivas ve ark., 2007). Lidster ve ark., (1979) ile Porritt ve Lidster (1978)'e göre, 4-6 gün boyunca $38^{\circ} \mathrm{C}$ 'de tutulan elmalarda titrasyon asitliği açısından bir düşüş yaşanmıştır. Boylston ve ark., (1994) depolama süresinin uzunluğunun ya da depolama koşullarının, 'Gala' çeşidi elmaların çözünebilir kuru madde konsantrasyonlarını ve titrasyon asitlik derecesini etkilemediğini belirlemişlerdir (Olivas ve ark., 2007).

\section{Ağırlık Kaybı}

Meyve ve sebzelerin ağırlığı hasat sonrası devam eden solunumlarından ötürü ve de kaybettikleri sudan dolayı azalmaktadır. Ürünlerin ağırlığında meydana gelen bu azalmalar muhafaza süresi içerisinde ekonomiye büyük zarar vermektedir. 
$\mathrm{Bu}$ nedenle meyve ve sebzeler için belirlenen muhafaza süresi önemlidir. Yapılan çalışmada K, SA ve SAS kaplanan elma örneklerinin ağırlıklarında değişim görülmemiştir. Yani, Kays, (1991) tarafından belirtilen \%4-6 olan kritik limitin altında belirlenmiştir. Benzer durum Karagöz ve Demirdöven (2019), kitosan ve stevia kombinasyonlarının taze kesilmiş Amasya elması üzerinde yaptığı çalışmada görülmüştür. Bu durumun depolama süresinin kısa olmasına bağlı olabileceği gibi elma örnekleri için uygun özellikte MAP ambalajının seçime bağlı olarak da gerçekleştiği düşünülmektedir.

\section{Doku Değeri}

Film kaplı elma dilimlerinin doku değerleri incelendiğinde depolama başlangıcı ve depolama sonu doku değeri arasındaki fark önemli bulunmamıştır $(\mathrm{P}>0.05)$. Ancak kontrol örneğinde bir düşüş söz konusudur ( $\mathrm{P} \leq 0.05)$ (Şekil 3).

Hem sodyum aljinat, hem de sodyum aljinat-stevia ile kaplanan elmalarda, kaplama sonrasında kontrol örneğine göre meyve sertliğinin azaldığı belirlenmiştir. Gün bazında değerlendirildiğinde ise depolama başlangıcında kontrol örneği film kaplı örneklere göre daha yüksek değerler vermiştir $(\mathrm{P} \leq 0.05)$. Çünkü taze doğranmış meyvelerde dokunun bozulması ve sertliğin kaybolması doğrama ile metabolik faaliyetlerin hızlanması ile hücre duvarının bozulması sonucu oluşmaktadır. Sert yapının kaybolması, pektik enzimlerinin aktivitesi ile ilgilidir. Olgunlaşma sırasında bu enzimlerin sentezinde artış meydana gelerek meyve dokusunun yumuşamasına neden olur (Özdemir, 2015). Bu nedenle taze kesilmiş meyve ve sebzelerin paketlenmeden önce enzim faaliyetinin yavaşlatılması için fazla su ve çözeltilerden uzaklaştırılması gerekmektedir. Son üründe kalan su ayrıca mikroorganizmaların gelişmesine ve tekstürün bozulmasına sebep olabilmektedir (James ve Ngarmsak, 2010). Çalışmada kullanılan sodyum aljinat hidrokolloid yapıda bir polisakkarittir. Küp haline getirilmiş elmaların merkezinden yüzeye doğru hareket eden suyun yüzeyde sodyum aljinat tarafından tutularak ve diğer günlerde ambalajın da etkisiyle (nem geçiş hızının az olması) yüzeyde bir su birikintisi oluşturduğu, enzim ve mikroorganizma faaliyetlerini tetiklediği, bunun sonucunda da meyvenin yumuşadığı düşünülmektedir.

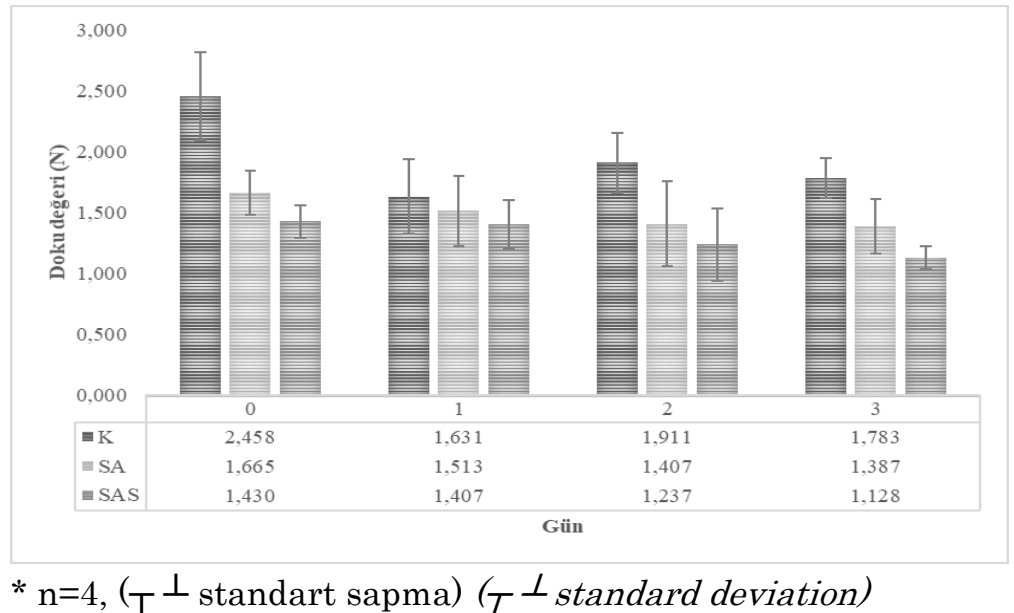

Şekil 3. Örneklere ait doku değerleri; K (Kontrol), SA (Sodyum aljinat), SAS (Sodyum aljinat-stevia)

Figure 3. Hardness values of samples; C (Control), SA (Sodium alginate), SAS (Sodium alginate-stevia) 
SA ve SAS örneğindeki değerler genel olarak karşlaştırıldığında, SAS örneği daha düşük değerler göstermiştir. Buradan anlaşlacağı üzere stevia meyve dokusunu etkilemiş, meyve dokusunun direncini sodyum aljinat kaplamaya göre daha da azaltmıştır. 0.gün/3.gün meyve dokusu değerleri kontrol, sodyum aljinat ve sodyum aljinat+stevia için sırasıyla $2.46 / 1.78,1.67 / 1.39$ ve $1.43 / 1.13$ olarak bulgulanmıştır.

Sodyum aljinat filmi meyve sertliğini düşürmüştür. Ancak sodyum aljinat filminin neden olduğu bu bariz yumuşama $\mathrm{CaCl} 2$ ilavesi ile giderilebilir. Rojas Grau ve ark., (2007) yaptıkları bir çalışmada, kesilmiş taze elmalara uygulanan aljinat veya jellan bazlı yenilebilir kaplamaların, formülasyon içeriğinde $0.025 \mathrm{ml}$ ayçiçeği yağı / $100 \mathrm{ml}$ olması durumunda, nem kaybı kontrolünde etkili olduğu belirtilmiştir. Böylece, kaplanmış meyvenin yağa bağlı nem tutma özelliği ile dokuyu koruyabilmiştir.

Rojas Grau ve ark., (2008), ayçiçek yağına ek olarak elmaları \%1 N-asetilsistein+\%2 $\mathrm{CaCl} 2$ çözeltisine daldırma uygulamışlardır. Çalışmalarında elma dilimlerine uygulanan yenilebilir kaplama kullanımı ile dokunun korunması arasında önemli farklılık tespit etmişlerdir $(\mathrm{P}<0.05)$. Tüm depolama süresi boyunca hem aljinat hem de jellan kaplama ile elma dilimlerinin sertliklerinin korunmasında olumlu sonuç aldıklarını ifade etmişlerdir. Ayrıca çalışmalarında kaplanmamış elma dilimlerinin sertliğinin, 23 günlük depolama süresi boyunca 10.19'dan 5,30 N'a düştüğünü ve dokuların önemli derecede yumuşama gösterdiğini belirtmişlerdir. Bununla birlikte Salvia-Trujillo ve ark., (2015), yenilebilir kaplamaların, limon otu yağı konsantrasyonun ve de limon otu yağı'nın parçacık boyutunun, elma dilimlerinin sertliğine önemli derecede etki ettiğini bildirmiştir. Ayrıca Maftoonazad ve ark., (2008), metil selüloz ve sodyum aljinat kaplamalarının şeftalide doku korunumunda etkili olduğunu ifade etmişlerdir.

\section{Renk Değeri}

Kesilmiş taze elmaların esmerleşmesi temelde meyve dokusunun parlaklığında azalma ( $L^{*}$ değeri) ve aynı zamanda Hue açısı değerinde düşüş anlamına gelen $a^{*}$ (kırmızılık) değerlerindeki artış ile belirtilmektedir (Soliva-Fortuny ve ark., 2001). Şekil 4'de görüldügü üzere depolama süresi sonunda K, SA ve SAS örneklerinin meyve eti $L^{*}$ değerinde düşüş, $a^{*}$ ve $b^{*}$ değerinde ise artış görülmüştür $(\mathrm{P} \leq 0.05)$. Bununla birlikte SAS kaplı elma dilimlerinin meyve eti $L^{*}$ değeri yüksek ve $b^{*}$ değerleri düşük belirlenmiştir. Oluşan bu farklılığın film formülasyonunun $L^{*}$ ve $b^{*}$ değerlerinin farklı olmasından ileri geldiği düşünülmektedir. Benzer sonuç başka bir çalışmada da elde edilmiştir (Kargöz ve Demirdöven, 2019). Bununla birlikte Fontes ve ark., (2008), 9. günden itibaren aljinat kaplamanın kontrol örneklerinin değerlerine kıyasla daha düşük parlaklık değerleri gösterdiğini bildirmişlerdir ve bu durum aljinat solüsyonunun sarı renginden dolayı düşük $L^{*}$ değerleri göstermesine bağlanmıştır. 


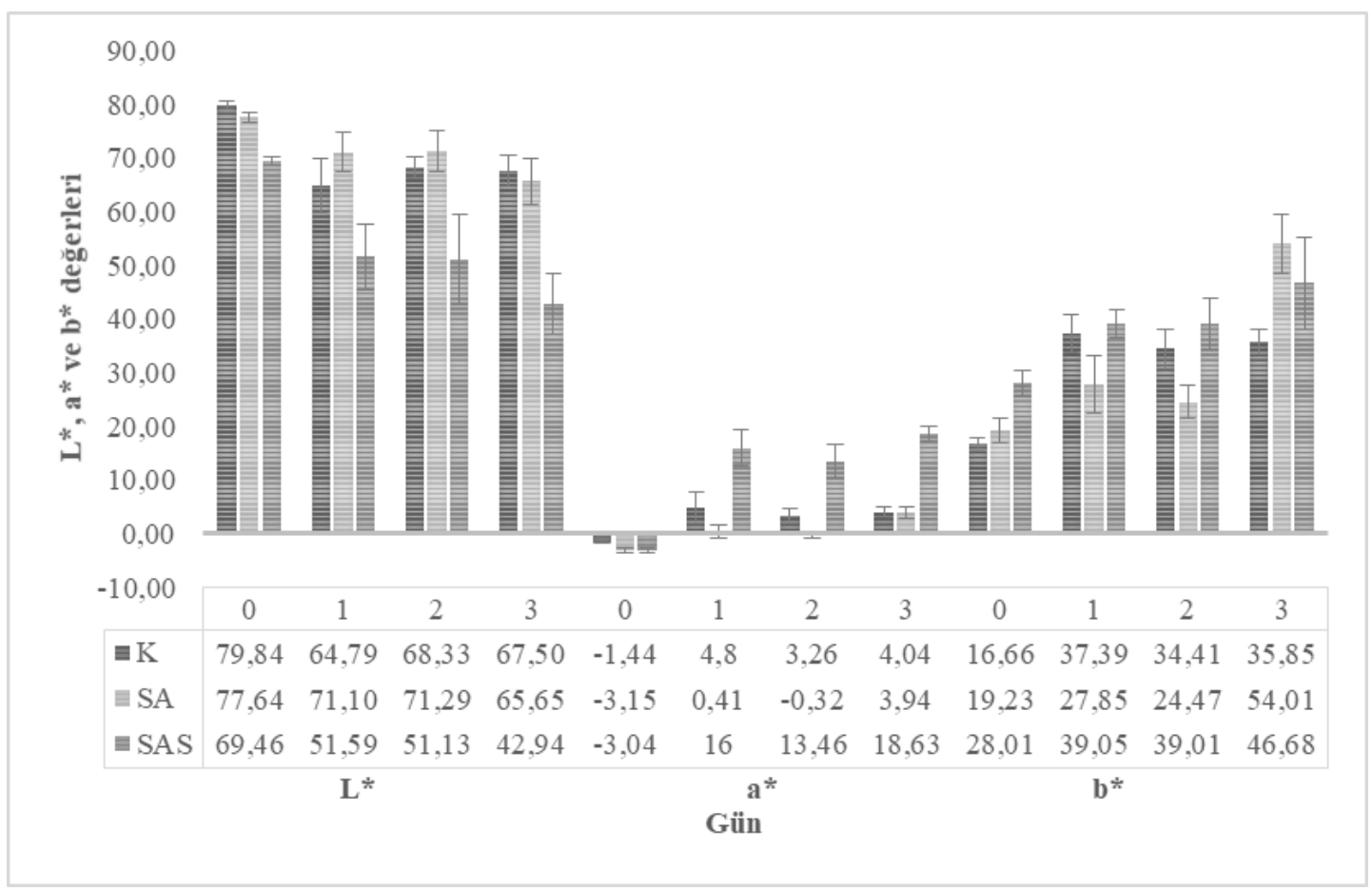

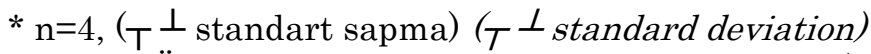

Şekil 4. Örneklere ait $L^{*}, a^{*}$ ve $b^{*}$ değerleri; K (Kontrol), SA (Sodyum aljinat), SAS (Sodyum aljinat-stevia)

Figure 4. $L^{*}, a^{*}$ and $b^{*}$ values of samples; $C$ (Control), $S A$ (Sodium alginate), $S A S$ (Sodium alginate-stevia)

Montero-Calder'on ve ark., (2008), kesilmiş taze ananasları kalsiyum klorür içeren sodyum aljinat ile kaplamışlar ve $5{ }^{\circ} \mathrm{C}$ 'de 20 gün depolama boyunca $L^{*}$ değerinin $\% 22$ oranında, $b^{*}$ değerinin \%29 oranında azaldığını belirtmişlerdir. Araştırmacılara göre $L^{*}$ ve $a^{*}$ değerindeki bu farklılıklar sarı-beyaz opak renkten yarı saydam sarı renge dönüşen meyve etinden kaynaklanmaktadır. Bu durumun nedeni olarak da esmerleşme reaksiyonları ve polifenoloksidaz enzim aktivitesi gösterilmiştir (Bierhals ve ark., 2011). Buna karşın Hui-Min ve ark., (2009), sodyum aljinat kaplama ve sodyum aljinatın kullanıldığı diğer kaplamaların $L^{*}$ değerinin düşmesine, $a^{*}$ ve $b^{*}$ değerlerinin ise artmasina neden olduğunu vurgulamıştır.

Meyve eti $\Delta \mathrm{E}, \Delta \mathrm{C}$, Hue açısı değerlerindeki değişimlere ilişkin bulgular Çizelge 1'de verilmiştir. Hesaplamalar, kontrol grubunun $L^{*}$, $a^{*}$ ve $b^{*}$ değerleri referans alınarak yapılmıştır. 
Çizelge 1. Örneklere ait $\Delta \mathrm{E}, \Delta \mathrm{C}$ ve $\mathrm{Hue}^{\circ}$ değerleri; $\mathrm{K}$ (Kontrol), SA (Sodyum aljinat), SAS (Sodyum aljinat-stevia)

Table 1. $\triangle E, \triangle C$ and Hueo values of samples; $C$ (Control), $S A$ (Sodium alginate), $S A S$ (Sodium alginate-stevia)

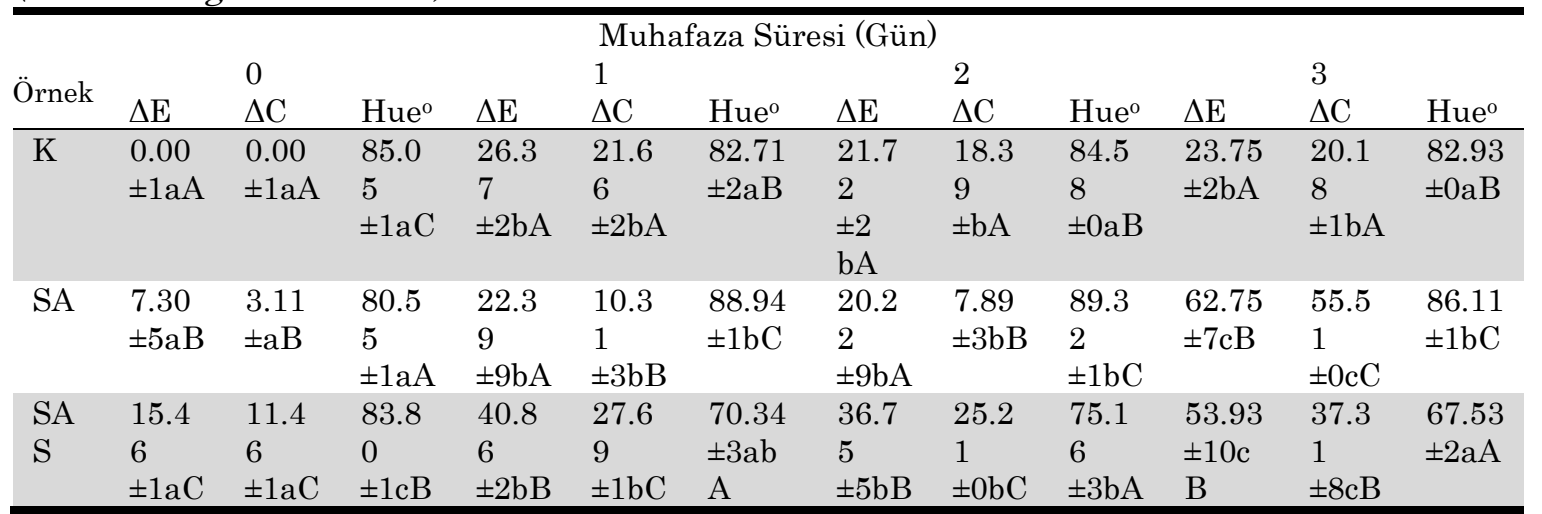

$\mathrm{n}=4$, ( \pm standart sapma), a, $\mathrm{b} \ldots \leq 0.05$ aynı satırdaki, A, B, C $\leq 0.05$ aynı sütundaki farklılıkları gösterir.

$n=4$, ( \pm standard deviation), a, $b \ldots \leq 0.05$ represent the differences in the same column, ${ }^{A}, B, C \leq 0.05$,

respectively, on the same line.

Kontrol, sodyum aljinat ve sodyum aljinat-stevia örneklerinin meyve eti $\Delta \mathrm{E}$ ve $\Delta \mathrm{C}$ değeri değerlendirildiğinde tüm örneklerin meyve eti $\Delta \mathrm{E}$ ve $\Delta \mathrm{C}$ değerlerinde artış gözlenmiştir $(\mathrm{P} \leq 0.05)$.

Depolama başlangıcı SAS örneğinin $\Delta \mathrm{E}$ ve $\Delta \mathrm{C}$ değeri diğer örneklerden yüksektir. SA ve SAS örneğinin 0 . gün $\Delta \mathrm{E}$ değeri sırasıyla 7.30 ve $15.46, \Delta \mathrm{C}$ değeri sirasiyla 3.11 ve 11.46 olarak bulgulanmıştır (0.gün kontrol örneği referans alınmıştır; 0.00). Bu farklılık stevianın kendine has olan renginden kaynaklanmaktadır. Tüm örneklerin depolama sonundaki $\Delta \mathrm{E}$ ve $\Delta \mathrm{C}$ değerleri incelendiğinde film kaplı örneklerin kontrol örneğine göre yüksek bir değer gösterdiği görülmektedir ve aralarındaki fark istatistiki olarak önemlidir $(\mathrm{P} \leq 0.05)$. $\mathrm{K}, \mathrm{SA}$ ve $\mathrm{SAS}$ örnekleri için $\Delta \mathrm{E}$ değerleri sırasıyla $23.75 ; 62.75 ; 53.93$ ve $\Delta \mathrm{C}$ değerleri sırasıyla $20.18 ; 55.51 ; 37.31$ olarak tespit edilmiştir. Verilerde görüldüğü üzere en büyük renk farklılığı SAS örneğinde görülmüştür ve SAS örneği depolama boyunca bu farklllı̆̆ı sürdürmüştür. Ayrıca kontrol ve SAS örneklerinin meyve eti Hue açısı değerlerinde düşüş gözlenmiştir ve depolama başlangıcı ile depolama sonu arasındaki fark istatistiki olarak önemlidir $(\mathrm{P} \leq 0.05)$. Ancak SA örneğinin Hue açısı değeri 1.gün yükselmiş, daha sonra bir düşüş göstermiştir. SAS örneklerin depolama sonu Hue açısı değeri diğer örneklere göre düşük çıkmıştır.

Chiumarelli ve ark., (2011), $\Delta \mathrm{C}$ değerleri ile ilgili olarak, manyok nişastası ve aljinat kaplamaların kullanımının mangolarda renk yoğunluğunu etkilemediğini ve depolama süresinin tüm işlemler için önemli bir etkiye sahip olduğunu ve depolama boyunca $\Delta \mathrm{C}$ değerinde bir azalma olduğunu belirtmiştir. Aljinat solüsyon renginin muhtemelen $\Delta \mathrm{C}$ parametresini etkilediğini ve bu polisakaritle kaplanan numuneler için daha düşük değerler elde edildiğini belirtmişlerdir.

\section{Duyusal Analiz}

Depolama başlangıcında film kaplı ve kaplanmamış olarak duyusal değerlendirilmesine ilişkin bulgular Çizelge 2'de verilmiştir. Depolamanın diğer günlerinde duyusal kalitenin bozulması nedeniyle duyusal analiz yapılmamıştır. 
Çizelge 2. Örneklere ait duyusal analiz verileri (0-5p); K (Kontrol), SA (Sodyum aljinat), SAS (Sodyum aljinat-stevia)

Table 2. Sensory analysis values of samples (0-5p); $C$ (Control), SA (Sodium alginate), $S A S$ (Sodium alginate-stevia)

\begin{tabular}{lllllll}
\hline Örnek & Tatlılık & Ekşilik & $\begin{array}{l}\text { Elma } \\
\text { aroması }\end{array}$ & Gevreklilik & Sertlik & $\begin{array}{l}\text { Kabul } \\
\text { edilebilirlik }\end{array}$ \\
K & $4.8 \pm 0.4 \mathrm{~B}$ & $0.4 \pm 0.7 \mathrm{~A}$ & $4.7 \pm 0.5 \mathrm{~B}$ & $4.1 \pm 0.3 \mathrm{~B}$ & $3.3 \pm 0.8 \mathrm{~B}$ & $4.8 \pm 0.4 \mathrm{~B}$ \\
$\mathrm{SA}$ & $4.4 \pm 0.5 \mathrm{~B}$ & $0.2 \pm 0.4 \mathrm{~A}$ & $4.3 \pm 0.5 \mathrm{~B}$ & $3.4 \pm 0.5 \mathrm{~A}$ & $2.7 \pm 0.7 \mathrm{~A}$ & $3.9 \pm 0.6 \mathrm{~B}$ \\
SAS & $3.3 \pm 0.5 \mathrm{~A}$ & $0.9 \pm 0.9 \mathrm{~A}$ & $2.6 \pm 0.5 \mathrm{~A}$ & $3.3 \pm 0.7 \mathrm{~A}$ & $2.2 \pm 0.7 \mathrm{~A}$ & $1.1 \pm 0.8 \mathrm{~A}$ \\
\hline
\end{tabular}

${ }^{*} \mathrm{n}=9$, ( \pm standart sapma), A, B, C $\leq 0.05$ aynı sütundaki farklllıkları gösterir.

${ }^{*} n=9$, ( \pm standard deviation), $A, B, C \leq 0.05$ represent the differences in the same column respectively

Genel itibariyle panelistler, SA ile kaplanmış elmaların tatlılık, ekşilik ve elma aromasının, kontrol ile benzerlik gösterdiğini belirtmişlerdir ( $\mathrm{P}>0.05)$. Bununla birlikte panelistler kontrol örneğinden sertlik ve gevreklik özellikleri bakımından farklı olduğunu belirtmişlerdir ( $\mathrm{P} \leq 0.05)$. SA örneğinin kontrole göre biraz daha yumuşak bir dokuda olduğunu, elma dışındaki filmin hissedildiğini ve yapışkanımsı bir his verdiğini, bunun kabul edilebilirliği etkilediğini ifade etmişlerdir $(\mathrm{P} \leq 0.05)$. SAS örneklerinin ise kabul edilebilirliğinin çok daha düşük olduğunu çünkü film tabakasının SA'dan bile fazla hissedildiğini, SA'ya göre daha yapışkan olduğunu ayrıca stevianın kokusu, tadı ve renginin belirgin olduğunu vurgulamışlardır $(\mathrm{P} \leq 0.05)$. Stevia tatlılık ekşilik, elma aroması ve kabul edilebilirliği etkilemiştir.

\section{SONUÇ}

Film kaplama solunum hızını yavaşlatmıştır. Ancak stevia, karbondioksit üretim hızını sodyum aljinat kaplamaya göre arttırmıştır. Kaplama çözeltisi hazırlandığı sırada sadece sodyum aljinat içeren kaplama çözeltisi ile sodyum aljinata stevia ilave edilmiş film çözelti yapısının aynı olmadığı, kaplama sırasında jelleşmeler tespit edildiği ve bunun sonucu olumsuz etkilediği düşünülmektedir. Solunum yavaşlatılması bir ürünün raf ömrünün uzatılmasında etkilidir. Bu nedenle film kaplamanın bu etkisi dikkate alınmalıdır. Film kaplama aynı zamanda içerisinde bulunan askorbik asit nedeniyle titrasyon asitliğini arttırmıştır. Kontrol ve film kaplı örneklerde ağırlık kaybı görülmemiştir. Solunum ve nem kaybı ile birlikte gelen ağırlık kaybının azaltılması ekonomik kayıpları en aza indirgeyecektir. Bu durum depolama süresinin doğru seçildiğinin bir göstergesidir. Ancak meyve sertliği korunamamıştır. Bu durumun daldırma çözeltisi içerisine $\mathrm{CaCl}_{2}$ ilavesi ile giderilebileceği düşünülmektedir. Meyve rengi kontrol örneklerinde çok kısa bir süre sonra enzimatik esmerleşme ile değişmiştir. Ancak film kaplı ürünlerde enzimatik esmerleşme görülmesi 9-12 saat sonra gerçekleşmiştir. Bu süre tamamlayıcı çalışmalar ile uzatılabilecektir. Depolama süresi sonunda K, SA ve SAS örneklerinin meyve eti $L^{*}$ değerinde düşüş, a* ve b* değerinde ise artış görülmüştür $(\mathrm{P} \leq 0.05)$. SAS örneğinin meyve eti $L^{*}$ değerleri diğer örneklere göre düşük ve $b^{*}$ değerleri diğer örneklere göre yüksek çımıştır $(\mathrm{P} \leq 0.05)$. Bu sonuç stevianın kendine has renginden kaynaklanmaktadır. Ayrıca stevia otsu tadı ve kokusu nedeniyle tüketicileri olumsuz etkilemiştir. Sonuç olarak daha yüksek kalitede ürün eldesi için kaplanmış elmaların raf ömrünü uzatmak amacıyla; film formülasyonuna yardımcı madde ilavesi koşulları iyileştirebilir veya kaplanmış elmalarda aktif MAP uygulaması yapılabilir. 


\section{ÇIKAR ÇATIŞMASI}

Yazarlar olarak herhangi bir çıkar çatışması olmadığını beyan ederiz.

\section{YAZAR KATKISI}

Şeyda Karagöz: Araştırma ve literatür taraması, analizlerin yapılması ve sonuçların değerlendirilerek makale haline dönüştürülmesi,

Aslıhan Demirdöven: Araştırmanın yürütülmesi ve sonuçlarının yorumlanması, makalenin genel kontrolü

\section{KAYNAKLAR}

Anonim (1991). Minolta CR-300 Chromameter operator's instruction manual. Minolta Crop., Ramsey, NJ.

Anonim (1996). Hunter lab color scale applications note, Hunter associates Lab., Virginia, 8 (9): 1-4.

Anonim (2002). Zwick Z0.5 Universal tester operator's instruction manual.

Altuğ T ve Elmacı Y (2005). Gıdalarda duyusal değerlendirme. Meta Basım Matbaacılık Hizmetleri, Bornova-İzmir, Türkiye, 133 s. ISBN: 9944566087.

Baldwin EA, Nisperos-Carriedo MO and Baker RA (1995). Edible coatings for lightly processed fruits and vegetables. Hortscience, 30: 35-38.

Barba FJ, Grimi N and Vorobiev E (2015). Evaluating the potential of cell disruption technologies for green selective extraction of antioxidant compounds from Stevia rebaudiana Bertoni leaves. Journal of Food Engineering, 149: 222-228.

Batu A and Demirdöven A (2010). Effects of modified atmosphere packaging and cold storage on sensory qualities of apples. Yüzüncü Yll Üniversitesi Tarım Bilimleri Dergisi, 20: 58-67.

Bierhals VS, Chiumarelli M and Hubinger MD (2011). Effect of cassava starch coating on quality and shelf life of fresh-cut pineapple (Ananas comosus L. Merril cv "Perola"). Journal of Food Science, 76: 62-72.

Boylston TD, Kupferman EM, Foss JD and Buering C (1994). Sensory quality of Gala apples as influenced by controlled and regular atmosphere storage. Journal of Food Quality, 17: 477-494.

Carbonell-Capella JM, Buniowska M, Esteve MJ and Frigola A (2015). Effect of Stevia rebaudiana addition on bioaccessibility of bioactive compounds and antioxidant activity of beverages based on exotic fruits mixed with oat following simulated human digestion. Food Chemistry, 184: 122-130.

Cemeroğlu B, Yemenicioğlu A ve Özkan M (2001). Meyve ve sebzelerin bileşimi soğukta depolanmaları. Gıda Teknolojisi Derneği Yayınları, No: 24, 328 s, Ankara.

Cemeroğlu B (2004). Meyve ve Sebze İşleme Teknolojisi. Gıda Teknolojisi Derneği Yayınları, No: 38, 690 s, Ankara.

Chen C, Peng X, Zeng R, Chen M, Wan C and Chen J (2016). Ficus hirta fruits extract incorporated into an alginate-based edible coating for Nanfeng mandarin preservation. Scientia Horticulturae, 202: 41-48.

Chiabrando V and Giacalone G (2016). Effects of edible coatings on quality maintenance of fresh-cut nectarines. Emirates Journal of Food and Agriculture, 28 (3): 201-207.

Chiumarelli M, Ferrari CC, Sarantópoulos CIGL and Hubinger MD (2011). Fresh cut 'Tommy Atkins' mango pre-treated with citric acid and coated with cassava (Manihot esculenta Crantz) starch or sodium alginate. Innovative Food Science and Emerging Technologies, 12: 381-387.

Demirdöven A (2003). Tokat'ta yetistirilen bazı önemli meyve ve sebzelerin solunum hızlarının belirlenmesi üzerine bir araştırma. Yüksek Lisans Tezi, Gaziosmanpaşa Üniversitesi Fen Bilimleri Enstitüsü, Gıda Mühendisliği Anabilim Dalı, s. 98, Tokat.

Fişekci B (2013). Lor peynirinin raf ömrü üzerine modifiye atmosfer paketlemenin ve $\mathrm{CO}_{2}$ uygulamasının etkilerinin belirlenmesi. Yüksek Lisans Tezi, Süleyman Demirel Üniversitesi, Fen Bilimleri Enstitüsü, Gıda Mühendisliği Anabilim Dalı, Isparta.

Fontes LCB, Sarmento SBS, Spoto MHF and Dias CTS (2008). Preservation of minimally processed apple using edible coatings. Ciência e Tecnologia de Alimentos, 28: 872-880.

Gantait S, Das A and Mandal N (2015). Stevia: a comprehensive review on ethnopharmacological properties and in vitro regenerationjune. Sugar Tech, 17 (2): 95-106.

Hui-Min J, To H, Li-Ping L and Hai-Ying Z (2009). Effects of edible coatings on browning of fresh-cut peach fruits. Transactions of the Chinese Society of Agricultural Engineering, 25 (3): 282-286. 
İzli N ve Polat A (2016). Dondurarak kurutma yönteminin zencefilin kurutma karakteristikleri, renk, mikroyapı ve rehidrasyon özellikleri üzerine etkisi. Gaziosmanpaşa Üniversitesi Ziraat Fakültesi Dergisi, 33 (Ek sayı): 126-136.

James JB and Ngarmsak T (2010). Processing of freshcut tropical fruits and vegetables: A technical guide, Bangkok: RAP Publication. Food and Agriculture Organization of the United Nations Regional Office for Asia and the Pacific. ISBN 978-92-5-106712-3.

Karagöz Ş (2018). Stevia içeren yenilebilir film formülasyonlarının geliştirilmesi ve yenilebilir film kaplama ile modifiye atmosferde ambalajlama kombinasyonunun az işlem görmüş elmaların raf ömrüne etkileri. Doktora Tezi, Tokat Gaziosmanpaşa Üniversitesi, Fen Bilimleri Enstitüsü, Gida Mühendisliği Anabilim Dalı, Tokat.

Karagöz Ş and Demirdöven A (2019). Effects of some edible coating on quality of ready-to-eat Amasya apples. Gida, 44 (1): 60-70.

Kays SJ (1991). Postharvest physiology of perishable plant products. Van Nostrand Reinholt, Londan, $75^{-}$ 142 p. ISBN: 0442239122.

Lidster PD, Tung MA, Garland MR and Porritt SW (1979). Texture modification of processed apple slices by a postharvest heat treatment. Journal of Food Science, 44: 998-1007.

Luo MR (2006). Applying colour science in colour design. Optics \& Laser Technology, 38: $392-398$.

Maftoonazad N, Ramaswamy HS and Marcotte M (2008). Shelf-life extension of peaches through sodium alginate and methyl cellulose edible coatings. International Journal of Food Science \& Technology, 43: 951-957.

McGuire RG (1992). Reporting of objective color measurements. Hortscience, 27: 1254-1255.

Montero-Calderon M, Rojas-Graü MA and Martin-Belloso O (2008). Effect of packaging conditions on quality and shelf-life of fresh-cut pineapple (Ananas comosus). Postharvest Biology and Technology, 50: 182-189.

Olivas GI, Mattinson DS and Barbosa-Cánovas GV (2007). Alginate coatings for preservation of minimally processed 'Gala' apples. Postharvest Biology and Technology, 45(1): 89-96.

Oms-Oliu G, Soliva-Fortuny R and Martín-Belloso O (2008). Using polysaccharide-based edible coatings to enhance quality and antioxidant properties of fresh-cut melon. LWT-Food Science and Technology, 41 (10): 1862-1870.

Öz AT ve Süfer Ö (2012). Meyve ve sebzelerde hasat sonrası kalite üzerine yenilebilir film ve kaplamaların etkisi. Akademik Gıda, 10 (1): 85-91.

Özdemir KS (2015). Gıda ve biyoaktif gıda bileşenlerinin kaplanması: proses ve depolama stabilitesi üzerine etkileri. Doktora Tezi, Hacettepe Üniversitesi, Fen Bilimleri Enstitüsü, Gıda Mühendisliği Anabilim Dalı, Ankara.

Perez-Gago MB, Gonzalez-Aguilar GA and Olivas GI (2010). Edible coatings for fruits and vegetables. Stewart Postharvest Review, 6:1-4.

Pop OL, Vodnar DC, Suharoschi R, Mudura E and Socaciu C (2015). L. plantarum ATCC 8014 entrapment with prebiotics and lucerne green juice and their behavior in simulated gastrointestinal conditions. Journal of Food Process Engineering, 39 (5): 433-441.

Rojas-Graü MA, Raybaudi-Massilia RM, Soliva-Fortuny R, Avena-Bustillos RJ, McHugh TH and MartínBelloso O (2007). Apple puree-alginate coating as carrier of antimicrobial agents to prolong shelf-life of fresh-cut apples. Postharvest Biology and Technology, 45 (2): 254-264.

Rojas-Graü MA, Tapia MS and Martín-Belloso O (2008). Using polysaccharide-based edible coatings to maintain quality of freshcut Fuji apples. Trends in Food Science \& Technology, 41: 139-147.

Rössle C, Brunton N, Gormley RT, Wouters R and Butler F (2011). Alginate coating as carrier of oligofructose and inulin and to maintain the quality of fresh-cut apples. Journal of Food Science, 76: H19-H29.

Sadler GD and Murphy PA (1998). pH and Titratable Acidity. Food Analysis, Ed: Suzanne Nielsen, S., Aspen Publishers, Inc., Gaithersburg, Maryland, 101-116.

Salvia-Trujillo L, Rojas-Graü MA, Soliva-Fortuny R and Martín-Belloso O (2015). Use of antimicrobial nanoemulsions as edible coatings: impact on safety and quality attributes of fresh-cut Fuji apples. Postharvest Biology and Technology, 105: 8-16.

Siddaramaiah, Swamy TMM, Ramaraj B and Lee JH (2008). Sodium alginate and its blends with starch: thermal and morphological properties. Journal of Applied Polymer Science, 109: 4075-4081.

Soliva-Fortuny RC, Grigelmo-Miguel N, Odriozola-Serrano I, Gorinstein S and Martín-Belloso O (2001). Browning evaluation of ready-to-eat apples as affected by modified atmosphere packaging. Journal of Agricultural and Food Chemistry, 49: 3685-3690. 
Stevens MA, Kader AA and Albright M (1979). Potential for increasing apple flavour via increasing sugar and acid content. Journal of the American Society for Horticultural Science, 104: 40-42.

Tapia MS, Rojas-Grau MA, Carmona A, Rodriguez FJ, Soliva-Fortuny R and Martin-Belloso O (2008). Use of alginate- and gellan-based coatings for improving barrier, texture and nutritional properties of freshcut papaya. Food Hydrocolloids, 22: 1493-1503.

Tavassoli-Kafrani E, Shekarchizadeh H and Masoudpour-Behabadi M (2016). Development of edible films and coatings from alginates and carrageenans. Carbohydrate Polymers, 137: 360-374.

Tokatlı K (2016). Karides atıklarından kitosan üretim koşullarının optimizasyonu ve kitosandan elde edilen yenilebilir film kaplamanın kirazların raf ömrüne etkisi. Doktora Tezi, Gaziosmanpaşa Üniversitesi, Fen Bilimleri Enstitüsü, Gıda Mühendisliği Anabilim Dalı, s. 202, Tokat.

Yılmaz L ve Elmacı Y (2018). Polifenol oksidaz enzimi ve inaktivasyon yöntemleri. Türk Tarım-Gıda Bilim ve Teknoloji Dergisi, 6 (3): 333-345. 